\title{
La educación superior en las cárceles. Los primeros pasos de Ecuador
}

\section{The higher education in prisons. The first steps of Ecuador}

Carlos Antonio Iturralde Durán, (carlos.iturralde@hotmail.com) (http://orcid.org/0000-0002-0300-7748)

Recibido: 2016-12-08 / Revisado: 2017-04-24 / Aceptado: 2017-08-28 / Publicado: 2018-01-01

\section{Resumen}

Alcanzar el Buen Vivir no es posible sin solucionar los problemas de exclusión social que requieren de la expansión de las libertades de grupos históricamente marginados, como lo son las personas privadas de libertad, muchas de las cuales antes de cometer actos delictivos vivieron en un entorno de violencia y pobreza, situación que en la cárcel punitiva concebida como una institución de castigo y denigración, se intensifica, acentuando conductas antisociales que crean círculos viciosos cuya ruptura se logra, entre otras cosas, proporcionándoles nuevos funcionamientos y capacidades, por lo cual la educación inclusiva en igual calidad que la ofertada en la vida libre pero con diseños curriculares y metodológicos específicos que garanticen la transferencia efectiva de conocimientos hacia este grupo, es clave, constituyéndose en el ejercicio de un derecho humano que dignifica a la vez que rehabilita, siendo la educación superior la de mayor impacto transformador. Ecuador inició un primer pilotaje otorgando becas a un grupo de presos para acceder a estudios universitarios en contexto de encierro, plan que debe superar diversos obstáculos requiriendo de la coordinación interinstitucional y del compromiso de la sociedad para que rinda los resultados deseados, contribuyendo a convertir a las prisiones en verdaderos Centros de Rehabilitación Social y al Sistema de Rehabilitación Social en un promotor de los derechos humanos y el Bien Vivir.

Descriptores: Buen Vivir, capacidades, libertades, educación superior, derechos humanos, cárcel.

\begin{abstract}
Achieving Good Living is not possible without solving the social exclusion problems that require the expansion of the freedoms of historically marginalized groups, such as the people deprived of liberty, many of them, before committing criminal acts, they lived in an environment of violence and poverty, situation that in punitive jail is conceived as an institution of punishment and denigration, intensifies, accentuating antisocial behaviors that create vicious circles which rupture is achieved, among other things, by providing them new functions and capabilities, so that inclusive education in the same quality as offered in free life but with specific curricular and methodological designs that guarantee the effective transfer of knowledge to this group, it is key, constituting itself in the exercise of a human right that dignifies at the same time that it rehabilitates, being the higher education the one with the greatest transformer impact. Ecuador began a
\end{abstract}

Forma sugerida de citar: Iturralde, C. A. (2018). La educación superior en las cárceles. Los primeros pasos de Ecuador. Alteridad, 13(1), 84-95. https://doi.org/10.17163/alt.v13n1.2018.06. 
first pilot giving scholarships to a group of prisoners to access to university studies in the context of confinement, a plan that must overcome various obstacles requiring interinstitutional coordination and the commitment of society in order to yield the desired results, contribut-

\section{Introducción}

Es reconocido que la educación incrementa la capacidad para funcionar, expandiendo la libertad de los individuos para alcanzar la vida que valoran, acercando a las personas y a la sociedad a la consecución del Buen Vivir (London y Formichella, 2006).

Sus beneficios son múltiples abarcando la dimensión económica, creando capital humano, mejorando las rentas individuales y nacionales; política, fomentando la participación ciudadana y la expresión pública en democracia; y social, formando la conciencia colectiva, la cohesión social y mejorando el acceso a servicios fundamentales como la salud y la instrucción formal; por lo cual se considera un activo intangible que contribuye a la reducción del traspaso intergeneracional de la desigualdad, y aún más importante, un derecho humano fundamental cuya exclusión deja a la persona al margen del desarrollo y la sociedad (Iturralde, 2005).

Por su importancia, la UNESCO en 1990 planteó el reto de otorgar educación de calidad para todos, el cual fue bien recibido por los países miembros quienes han diseñado estrategias en cooperación con actores públicos y privados, nacionales e internacionales, para ampliar la cobertura hacia grupos marginados que no han podido ejercer este derecho, y aunque los resultados entre los años 2000-2015 muestran avances, se advierte que aún falta mucho por hacer (UNESCO, 2015).

Entre los grupos excluidos se encuentran las personas privadas de la libertad (PPL), quienes están recluidos en centros de rehabilitación social (CRS), y aunque han perdido su derecho ambulatorio, aún mantienen la mayoría de sus ing to convert the prisons in real Social Rehabilitation Centers and to the Social Rehabilitation System in a promoter of the human rights and Good Living.

Keywords: Good Living, capabilities, freedoms, higher education, human rights, jail.

derechos, como lo es el acceso a educación de calidad (Scarfó, 2003).

En Ecuador, la Constitución reconoce a la educación como un derecho fundamental, y la educación de calidad para todos se cristaliza en los objetivos de desarrollo del Plan Nacional para el Buen Vivir (PNBV), pues es una condición necesaria para alcanzar la visión de desarrollo nacional, esta es "la consecución del buen vivir de todas y todos; la expansión de sus libertades y potencialidades en paz y armonía con la naturaleza; y la prolongación indefinida de las culturas humanas" (Correa, 2008, p. 43).

Estas directrices han permitido que instituciones como el Ministerio de Justicia, Derechos Humanos y Cultos (MJDHC), la Secretaría Nacional de Educación Superior, Ciencia, Tecnología e Innovación (SENESCYT), entre otras, en cooperación con instituciones educativas de diferentes niveles, creen espacios para que las PPL ejerzan su derecho a la educación e incrementen sus capacidades en miras de efectivizar su futura reinserción social.

Este artículo invita a reflexionar sobre la importancia constitutiva e instrumental que tiene la educación superior en la expansión de capacidades y libertades de grupos excluidos, específicamente de PPL; temática que se aborda desde la perspectiva de la equidad y la justicia social y que requiere considerar los principios éticos y de solidaridad que se ajustan al espíritu de los derechos humanos y a la visión del Buen Vivir.

\section{Buen vivir, capacidades y educación}

Buen Vivir, capacidades y educación son tres conceptos tan profundamente relacionados que 
no se puede concebir la existencia de uno sin la de los otros.

Se entiende por Buen Vivir a la "satisfacción de las necesidades, la consecución de una calidad de vida y muerte digna, el amar y ser amado, y el florecimiento saludable de todos y todas, en paz y armonía con la naturaleza y la prolongación indefinida de las culturas humanas" (Ramírez, 2008, p. 387), visión que se contempla en las Constituciones de Ecuador y Bolivia, y que coloca al Estado como promotor del desarrollo, encargado de dirigir el constructo social hacia la ampliación de capacidades y funcionamientos de la población, diseñando políticas que consideren la justicia distributiva para mitigar los graves problemas de exclusión (Celis y Sepúlveda, 2012).

El segundo término nace del enfoque de capacidades de Amartya Sen, Premio Nobel en Economía, quien sostiene que la capacidad de una persona se refleja en la libertad de alcanzar funcionamientos valiosos, y el conjunto de capacidades representa su libertad para conseguir aquello que valora; constituyéndose en determinantes de la calidad de vida a partir de la ampliación o restricción de libertades (Urquijo, 2014). Para comprender este enfoque, es necesario tener claro los siguientes conceptos:

- Funcionamiento. Hace referencia al estado de una persona y las acciones que logra realizar durante su existencia, por lo que el bienestar no se puede medir por la posesión de un bien o el nivel de renta, sino por el estilo de vida que se lleva con ellos lo cual depende del estado del individuo (Sen, 2000). Para ilustrar lo indicado se supondrán dos personas, A y $\mathrm{B}$, quienes obtienen una beca para estudiar en el exterior. Lamentablemente B es acusado de un delito y le imponen prisión preventiva. Para estos agentes, la beca es valiosa por lo que pueden ser o hacer con ella, por tal motivo, en la fecha del viaje, aunque ambos tienen el ticket aéreo y los fondos que financian el estudio, sólo es útil para A.
- Capacidades. Es el conjunto de funcionamientos, es decir, las habilidades físicas, legales e intelectuales que les dan la posibilidad de realizar actos para conseguir la vida que valoran, esto es, el bienestar potencial (Flores, 2005). Siguiendo el ejemplo anterior, se asume que ha pasado un año, B ha resuelto su problema legal y ahora lucha contra las secuelas físicas, psicológicas, económicas y sociales ocasionadas por encierro, teniendo menos opciones que antes de perder su libertad. B se ha empobrecido. Simultáneamente, A regresó de sus estudios con más conocimientos que han incrementado sus opciones laborales, económicas, políticas, culturales y sociales, ya que sus nuevos funcionamientos le dan mayores capacidades y libertades para crear la vida que desea. A se ha desarrollado.

La filosofía del Buen Vivir recoge la propuesta de Sen reconociendo que no se puede concebir el desarrollo sin la expansión de las capacidades y oportunidades, agregando que la libertad, entendida como la realización de las capacidades humanas, está condicionada a la realización de las potencialidades de la sociedad (Ramírez, 2008).

La justicia social demanda que la libertad de las personas no dependa de las condiciones en que nacieron ni de las circunstancias desfavorables de su entorno, siendo el Estado responsable de crear un entorno equitativo a favor de los menos favorecidos, donde la educación juega un rol relevante.

La educación, como condición necesaria para el desarrollo, requiere la intervención pública para garantizar tanto su calidad en todos los niveles: primaria, secundaria y superior, como su cobertura universal, incluyendo a grupos históricamente discriminados, como las PPL, permitiéndoles ser verdaderos actores de su propio progreso, otorgándoles voz, un pensamiento crítico y la capacidad de transformar la realidad que 
los rodea en algo constructivo; y la educación superior, mediante el proceso de transferencia de conocimientos, destrezas y habilidades que derivan en funcionamientos especializados, es el nivel educativo que mayores aportes realiza para el desarrollo integral, contribuyendo a la ruptura del lazo que mantiene a los excluidos atados con la pobreza.

\section{Rompiendo el círculo de violencia}

Las políticas neoliberales implementadas en América Latina entre los años 80 y 90, resquebrajaron el Estado del Bienestar creando desigualdad y pobreza sobre grandes grupos humanos quienes quedaron excluidos de los beneficios del progreso, de la democracia y del goce íntegro de sus derechos, obligándolos a vivir debajo del umbral de la dignidad e incrementando los índices delictivos, ya que sin equidad no puede haber ni eficiencia ni seguridad (SENPLADES, 2012).

Los obstáculos para el desarrollo se correlacionan con la violencia de tal forma que la delincuencia se puede explicar por factores económicos (bajo crecimiento, concentración de la riqueza, desocupación, pobreza), demográficos (discriminaciones por raza, género, urbanidad, migración), educacionales (analfabetismo, baja escolaridad), de capital social (individualismo, poca solidaridad, desconfianza) complementados por factores de carácter disuasivo (Obando y Ruiz, 2007).

Parte de estos marginados que en libertad vivieron en el umbral de la pobreza caracterizada por el desempleo, falta de habilidades sociales, escaso acceso a la educación, entre otras violaciones de sus derechos, agravados en ocasiones por problemas mentales no tratados como ansiedad, depresión, etc., en muchos casos asociados a traumas de la infancia por provenir de hogares disfuncionales donde sufrieron abusos físicos, psicológicos e incluso sexuales; al cometer actos delictivos, fueron capturados y aglutinados en las cárceles, desapareciéndolos virtualmente de la sociedad, y de esta manera, ocultando par- cialmente los deplorable resultados sociales del modelo (INEA, 2013).

En prisión, el campo de tensión "más delirante y violento del aparato de poder" (Parchuc, 2015, p. 20), se agravan las condiciones de estos marginados expuestos al choque físico y psicológico del encierro, la convivencia forzada y la intensificación de la violación de sus derechos. Esta población "no deseada" inicia un proceso de desocialización, aislamiento, fractura familiar, restricción emocional y un brutal empobrecimiento que incrementa sus miedos, ansiedades, agresividad y consumo de drogas reduciendo aún más su autoestima y sus capacidades (Scarfó, 2008).

Cumplida la pena, la cárcel regresa a la sociedad a un ser en peor estado que el inicial, con marcadas tendencias antisociales, quien sufrirá por sus antecedentes delictivos de mayor marginación reproduciéndose el círculo: víctima (social) -victimario (delincuente)- víctima (de la cárcel), el cual no es concebible desde la perspectiva de los Derechos Humanos ni desde la filosofía del Buen Vivir.

La ruptura de este ciclo, que inicia con un déficit del derecho humano seguido de un déficit de seguridad humana, requiere de tres condicionantes necesarias (aunque pueden ser insuficientes):

- Dotar de nuevos funcionamientos a los excluidos, incrementando sus capacidades y libertades, lo cual se logra con Educación, pues su valor intrínseco e instrumental es la clave para todas las capacidades humanas (Nussbaum, 2006). La metodología para la transferencia de conocimientos debe diseñarse "a la medida", reconociendo las particularidades de esta población.

- Acompañar con asistencia y apoyo institucional a las ex-PPL que se reinsertan a la sociedad; pues enfrentan retos personales de índole social, económico y psicológico que motivan a la reincidencia delictiva, como lo son: cambiar círculos sociales para alejarse del mundo delictivo, pagar deudas adquiridas para su defensa jurí- 
dica además de asumir las multas que el Estado les impone por el delito; retornar a un hogar disfuncional, haber perdido su hogar e incluso no tener un lugar físico al cual volver; entre otros.

- Modificar la cultura vigente que crea estereotipos que devalúan a las PPL y ex-PPL ante la sociedad, estigmatizándolos (Pérez, 2013).

La reintegración de las PPL a la sociedad, sin concederles un umbral mínimo de capacidades y funcionamientos que les permitan ejercer la agencia y superar las causales que las impulsaron hacia la delincuencia, no es ética ni justa socialmente, pues volverían a ser excluidos y la probabilidad de fracaso del sistema sería casi una certeza.

El acceso a educación en las cárceles es clave, no sólo por su carácter terapéutico como elemento reinsertador, resocializador y rehabilitador, sino por ser el ejercicio de un derecho que reduce la situación de vulnerabilidad, debiendo abordarse desde dos perspectivas: la inclusiva, para que las PPL ingresen a un proceso que les permita alcanzar igualdad; y social, para democratizar conocimientos fomentando la participación ciudadana cuando recuperen la libertad.

Considerada un servicio no-negociable, pues debe ser inclusivo sin importar los recursos ni estado de los beneficiarios (Dias, 2008), la educación como derecho está consagrada en diferentes instrumentos políticos y jurídicos, entre los cuales se encuentran:

- La Declaración Americana de los Derechos y Deberes del Hombre, señala que toda persona tiene derecho a la educación bajo los principios de libertad, moralidad y solidaridad (OAS, 1948).

- La Convención Relativa a la Lucha Contra las Discriminaciones en la Esfera de la Enseñanza, manifestó que el acceso universal a la educación es responsabilidad prioritaria del Estado (UNESCO, 1960).

- El Pacto Internacional de Derechos Económicos, Sociales y Culturales adoptado por las Naciones Unidas, comprometió a los Estados a asegurar la disponibilidad, accesibilidad, aceptabilidad y adaptabilidad de la educación, sin discriminación (PIDESC, 1976).

- La Convención Americana sobre Derechos Humanos, conocida como Pacto de San José de Costa Rica, entró en vigencia en 1978 obligando al Estado a crear la normativa necesaria para el ejercicio de los derechos humanos, entre ellos, la Educación; complementada con el Protocolo de San Salvador (1988) donde se agregó que el Estado debe garantizar el ejercicio del derecho a la educación para todos (OEA, 1988).

- La Segunda Reunión de la Declaración Mundial sobre la Educación para Todos de la UNESCO (1990), indica que los excluidos son quienes más necesitan apoyo para superar su desventaja educativa y social, tornándose necesaria la acción del Estado.

- Los Estados participante del Proyecto Regional de Educación para América Latina y el Caribe (PRELAC), aceptaron ser garantes y reguladores del derecho a la educación de calidad para todos, reconociéndolo como un bien público que debe orientarse con mayor intensidad a los excluidos (UNESCO, 2007).

- La Declaración Universal de Derechos Humanos reza por el acceso a la educación de calidad para todos, sin exclusión por condición social, raza, género u otros. (UNESCO, 2008).

- La Conferencia Mundial sobre la Educación Superior (UNESCO, 2009) destacó que la ampliación del acceso a educación superior es responsabilidad de todos, en particular de los gobiernos; debiendo responder a objetivos de equidad, pertinencia y calidad; procurando la inclusión de los menos favorecidos.

Por lo expuesto, las PPL deben gozar de la misma educación que una persona en libertad, en igualdad sustantiva y sin discrimina- 
ción, entendiendo como no-discriminación a la garantía de que todos, con énfasis en los marginados, puedan acceder bajo estándares similares de calidad, a cualquier nivel educativo, incluyendo la educación superior.

Educar a los más necesitados para que aprendan a conocer, a hacer, a vivir juntos y a ser, es tal vez una de las misiones más relegadas en la sociedad pese a ser una de las más valiosas debido a las externalidades positivas que genera, como: crecimiento, profundización de la democracia, incremento de la productividad y los ingresos familiares, mayor cohesión social, desarrollo de ciencia y tecnología, beneficios intergeneracionales, reducción de la fertilidad, mejora de los estándares de nutrición y salud, etc.; empero también contribuye a la mitigación de externalidades negativas, como: reducción de la contaminación, reducción de la morbimortalidad infantil, reducción de la desocupación y la pobreza, reducción de la criminalidad, entre otros (Iturralde, 2005).

Los múltiples beneficios de la educación no se limitan al individuo, sino que se expanden hacia la comunidad, por lo que es deseable que todos, incluyendo las PPL, accedan a una educación de calidad de tal manera que los conocimientos y valores que se transmitan en las instituciones educativas fuera de la cárcel, se transfieran también dentro de sus muros.

Brindar educación superior a las presos es una forma de romper el círculo víctima-victimario-víctima en una estrategia ganar-ganar, a favor de las PPL y de la sociedad, ya que las nuevas capacidades generarían oportunidades futuras, mejorarían la participación democrática y los enriquecería como personas, creándoles un compromiso con la construcción de la paz, el desarrollo comunal y el respeto de los derechos humanos (Valenciano, 2009).

\section{Ecuador da sus primeros pasos}

La Constitución del 2008 marca un cambio de modelo, que requirió de reformas estructurales que intentan crear una sociedad más justa y soli- daria, recuperando el rol del Estado como promotor del desarrollo y promoviendo la planificación participativa desde la visión del Buen Vivir.

En ella se reconoce a la Educación como un derecho a lo largo de toda la vida, un deber ineludible e inexcusable del Estado y un área prioritaria de la política pública y la inversión estatal, garantizando la inclusión y la igualdad en acceso y calidad siendo uno de los ámbitos que conforman al Sistema Nacional de Inclusión y Equidad Social, lo cual incluye a la Educación Superior que se considera indispensable para la construcción del derecho del Buen Vivir (LOES, 2010).

La Carta Magna, en los artículos 5, 203 y 341, reconoce el derecho a la educación de las PPL y ordena la ejecución de planes educativos en los CRS, señalando al Estado como el actor responsable de la reinserción social y económica de este grupo vulnerable.

Los criterios de inclusión, justicia social $y$ equidad que priman en la normativa vigente, crean el marco para desarrollar políticas inclusivas que aborden la rehabilitación y reinserción social con una visión superior a la punitiva, siguiendo los lineamientos de la Convención Interamericana de Derechos Humanos, el Conjunto de Principios para la Protección de Todas las Personas Sometidas a Cualquier Forma de Detención o Prisión y el Pacto Internacional de Derechos Civiles y Políticos, que resaltan la importancia de readaptar socialmente a los internos.

El Código Orgánico Integral Penal, en el Artículo 704, agrega que el Sistema de Rehabilitación Social (SRS) debe promover la Educación Superior suscribiendo convenios con institutos o universidades; estrategia que procura efectivizar los pilares que constituyen al modelo penitenciario: privación de libertad-tratamiento-libertad (Messuti, y otros, 2014).

Consecuentes con la visión del Buen Vivir, el PNBV esboza objetivos de desarrollo que direccionan el accionar público, en el ámbito penitenciario, hacia la construcción de capacidades de las PPL y al robustecimiento del SRS, señalando como responsable y corresponsables, 
entre otros actores, al MJDHC y la SENESCYT, estando la Universidad en calidad de observancia. Entre los objetivos de desarrollo, políticas y lineamientos estratégicos que persiguen este propósito, destacan los siguientes:

Tabla 1. Objetivos de desarrollo, políticas y lineamientos para dar capacidades a las PPL

\begin{tabular}{|c|c|c|}
\hline Objetivo de Desarrollo & Política & Lineamiento estratégico \\
\hline \multirow{2}{*}{$\begin{array}{l}\text { Consolidar la transformación de } \\
\text { la justicia y fortalecer la seguridad } \\
\text { integral, en estricto respeto a los } \\
\text { derechos humanos }\end{array}$} & \multirow[b]{2}{*}{ Consolidar la transformación del SRS } & $\begin{array}{l}\text { b. Proteger los derechos de las } \\
\text { PPL... }\end{array}$ \\
\hline & & $\begin{array}{l}\text { e. Promover acciones de reinserción } \\
\text { social para las personas puestas en } \\
\text { libertad }\end{array}$ \\
\hline $\begin{array}{l}\text { Auspiciar la igualdad, la cohesión, } \\
\text { la inclusión y la equidad social y } \\
\text { territorial, en la diversidad }\end{array}$ & $\begin{array}{l}\text { Garantizar la igualdad en el acceso a ser- } \\
\text { vicios de salud y educación de calidad a } \\
\text { personas y grupos que requieren especial } \\
\text { consideración, por la persistencia de des- } \\
\text { igualdades, exclusión y discriminación }\end{array}$ & \\
\hline \multirow{2}{*}{$\begin{array}{l}\text { Fortalecer las capacidades y po- } \\
\text { tencialidades de la ciudadanía }\end{array}$} & $\begin{array}{l}\text { Alcanzar la universalización en el acceso a } \\
\text { la educación inicial, básica y bachillerato, } \\
\text { y democratizar el acceso a la educación } \\
\text { superior }\end{array}$ & $\begin{array}{l}\text { f. Generar mecanismos de acceso al } \\
\text { sistema educativo para la población } \\
\text { históricamente excluida... PPL... } \\
\text { mediante acciones afirmativas }\end{array}$ \\
\hline & $\begin{array}{l}\text { Promover la culminación de los estudios } \\
\text { en todos los niveles educativos }\end{array}$ & $\begin{array}{l}\text { h. Impulsar los programas de be- } \\
\text { cas... para promover el acceso, per- } \\
\text { manencia y reinserción de la pobla- } \\
\text { ción prioritaria y/o en condición de } \\
\text { vulnerabilidad. }\end{array}$ \\
\hline
\end{tabular}

Fuente: (SENPLADES, 2013)

Elaboración: el autor

Siete años después de haber creado el marco normativo para brindar Educación Superior a las PPL, inició el plan piloto para ofertar estudios universitarios dentro de las cárceles otorgando 435 becas, equivalente a menos del $2 \%$ de la población carcelaria, y cuya distribución no respondió a criterios de equidad entre CRS.

Este pilotaje es un esfuerzo interinstitucional entre el MJDHC, quien administra los CRS facilitando la logística, infraestructura y tecnologías, la SENESCYT que gestiona el proceso de capacitación y rendición de la prueba ENES además que asigna las becas a las PPL, y las Instituciones de Educación Superior (IES) encargadas de la docencia, asignando profesores, diseñando metodologías de enseñanza y evaluando conocimientos.

Las PPL, para acceder a las becas, debían ser bachilleres y aprobar el examen ENES. Cuando el número de PPL que cumplen ambos criterios sobrepasó la oferta de becas, se dio preferencia a quienes obtuvieron mayor calificación en el ENES permitiéndoles escoger primero la carrera. Por ello, existieron PPL que escogieron una carrera que no era su primera opción pues no había cupos en la que querían, mientras que otras no pudieron acceder a la universidad por la insuficiencia de becas.

Las PPL beneficiarias, al recobrar su libertad, mantienen la beca pudiendo continuar sus carreras en la IES donde fueron asignadas cuando estuvieron privadas de la libertad, estas son: la Escuela Superior Politécnica del Ejército (ESPE), la Universidad Politécnica Salesiana (UPS), la Universidad Católica de Santiago de Guayaquil (UCSG), y el Instituto Superior Tecnológico Simón Bolívar (ISTSB), como se observa en la tabla dos.

El modelo de gestión penitenciaria que se intenta implementar, tiene una concepción 
diferente del modelo punitivo, reorientando al sistema hacia la rehabilitación, siendo el acceso a educación de calidad uno de los pilares fundamentales del proceso.

Tabla 2. Carreras, año de inicio de clases y número de becas por Universidad y CRS

\begin{tabular}{|c|l|l|l|l|}
\hline Institución & \multicolumn{1}{|c|}{ Carreras } & \multicolumn{1}{c|}{ CRS } & \multicolumn{1}{c|}{ Año inicio } & \multicolumn{1}{c|}{ Becas } \\
\hline ESPE & Telemática, Logística y transporte & CRS Cotopaxi y CRS Latacunga & 2014 & 168 \\
\hline \multirow{2}{*}{ UPS } & $\begin{array}{l}\text { Administración de empresas, Contabili- } \\
\text { dad y auditoría }\end{array}$ & CRS Guayaquil No 1 & 2015 & 75 \\
\cline { 2 - 5 } & Administración de empresas & CRS Turi & 2016 & 64 \\
\hline \multirow{2}{*}{ UCSG } & $\begin{array}{l}\text { Administración, Derecho, Administra- } \\
\text { ción de empresas turísticas y hoteleras, } \\
\text { Contabilidad y auditoría, Marketing, Tra- } \\
\text { bajo social y desarrollo humano }\end{array}$ & CRS Regional Guayas & 2015 & 102 \\
\hline ISTSB & Mecánica industrial & CRS Regional Guayas & 2015 & 26 \\
\hline
\end{tabular}

Fuente: MJDHC, 2015

Elaboración: el autor

\section{Reflexiones finales}

La delincuencia es un problema social que erróneamente se ha intentado solucionar con la simple privación de la libertad de quien delinque, acción que a veces es socialmente aceptada, pese a ser una forma de violencia contra las PPL que desemboca en la extensión y empeoramiento de la situación negativa (Lutz, 2005).

Concebir las cárceles como cajas de Pandora que concentran los males de la humanidad, no sólo es incorrecto, sino también incompatible con los Derechos Humanos y la visión del Buen Vivir. Cambiar el nombre de la cárcel al de CRS no es algo simplemente discursivo, sino que entraña un profundo cambio institucional para crear un valor agregado social real en vez de convertirse en un ente reproductor de males.

Es aceptado que la exclusión social limita el desarrollo de capacidades que permiten el ejercicio de derechos, vulnerando las libertades individuales, por lo cual es una variable relevante al estudiar la delincuencia, no obstante, por sí sola resulta insuficiente dado que las personas que sufren de exclusión no deben ser consideradas delincuentes ipso-facto.
Colocar a una persona en la cárcel punitiva es exponerlo a un aislamiento social agresivo, sumándolo a una comunidad de marginados con culturas muy diversas en una convivencia forzada donde no predominan los valores socialmente aceptados, motivándolo al consumo de drogas, sin que tenga acceso a tratamientos reales de los desórdenes psicológicos o enfermedades psiquiátricas que pueda padecer, obligándolo a subsistir en un medio donde el saneamiento ambiental es escaso y las enfermedades abundantes, fragmentando el hogar de donde proviene; en fin, sometiéndolo a un nivel de violencia que erosiona sus capacidades, indiferentemente de lo desarrolladas que sean, entorpeciendo aún más el ejercicio de sus libertades que son flageladas desde la "formalidad de una institución", y seguramente lo continuarán siendo en libertad.

Respecto al último punto, se debe tener en cuenta que las PPL realizan fuertes gastos para su defensa, y si son declarados culpables, deben pagar multas e indemnizaciones cuando alcancen su libertad, periodo en que le imposibilitan el acceso al trabajo o les dan acceso sin remuneración, generando presiones económicas sobre su hogar, pues aún existen los costos por 
la educación de sus hijos, la alimentación de su familia, etc., conllevando en muchos casos a un sobreendeudamiento que deberá afrontar al salir de prisión, regresando a un hogar que ha cambiado durante su encierro, e intentando reinsertarse en una comunidad que lo rechaza por sus antecedentes penales.

Frecuentemente, para enfrentar la delincuencia se ha incurrido a una especie de venganza social que se cristaliza en la cárcel punitiva, que erróneamente intenta modificar el comportamiento delictivo basándose en la imagen de personas motivadas por el temor en lugar de factores constructivos, derivando en el fomento de la reincidencia delictiva (Larrauri, 1998); desconociendo que los victimarios fueron inicialmente víctimas, centrándose en la acción directa del delito a través de un inexorable sistema judicial, muchas veces carente de credibilidad, y no en los antecedentes que lo llevaron a realizar dichos actos que son y deben seguir siendo rechazados

Rechazar el acto, y no al ser humano que lo comete, es fundamental al momento de ejercer justicia, pues no se desea destruir a quien delinque (por eso en Ecuador no se acepta la pena de muerte) sino que se desea que esos actos delictivos se minimicen hasta llegar a anularse, debiendo eliminarse las motivaciones que influenciaron a su cometimiento, y paralelamente, otorgarle al interno nuevas capacidades y funcionamientos que hagan factible tal misión, lo que fue expresado por Nelson Mandela de esta manera: "Nadie nace odiando... La gente tiene que aprender a odiar, y si ellos pueden aprender a odiar, también se les puede enseñar a amar, el amor llega más naturalmente al corazón humano que su contrario" (1995, p. 144)

Entonces, las cárceles deben propender a la inclusión social a través del ejercicio de derechos y al desarrollo de capacidades, perspectiva que intenta plasmarse en el modelo de gestión penitenciaria donde la educación inclusiva tiene un rol protagónico y abarca a la Educación Superior.

Respecto a la oferta de Educación Superior en las cárceles, el MJDHC inició un plan piloto que consistió en otorgar 435 becas a internos de diferentes CRS del país quienes, siendo bachilleres, debieron obtener más de 600 puntos en el examen ENES, pero muchos de ellos, pese a que cumplieron ambos requisitos, quedaron excluidos porque el número de becas fue insuficiente y se privilegió a los mejores puntuados.

El proyecto es conceptualmente correcto, ajustándose a los objetivos de desarrollo y a la visión del Buen Vivir, pretendiendo potencializar las capacidades de los beneficiarios, y de tener éxito, incrementará sus libertades reduciendo la reincidencia; pero su implementación no es tarea fácil, pues requiere de la acción comprometida de varios actores en el largo plazo para poder superar las enraizadas barreras del entorno, entre ellas, las diferencias de misiones y visiones que derivan en el enfrentamiento: seguridad vs derechos, y castigo vs rehabilitación, que son producto de la inercia del antiguo modelo que se contrapone al que se desea instaurar.

Aunque no se creó una línea de base, se conoce que los beneficiarios del plan son un grupo heterogéneo que presenta diferentes dificultades, encontrándose PPL con maestría y otros que no han estudiado en años, muchos sin hábitos eficientes de estudio y sin conocer todos los beneficios que brinda la educación superior, todos agobiados por el estrés del encierro, lo que podría reducir su participación en el proceso. Por ello, la metodología de enseñanzaaprendizaje es clave y debería ser evaluada continuamente. La conformación de grupos de apoyo entre estudiantes PPL, como se realizó en el CRS Guayaquil Varones durante el proceso previo a la rendición del examen ENES que le permitió ser la cárcel con mayor cantidad de internos que aprobaron el test, fue una estrategia con buenos resultados por lo que su reactivación, para fomentar la cultura de estudio, es pertinente.

La dotación de materiales didácticos no ha sido del todo superada, provocando dificultades ya que las PPL no pueden realizar actos tan básicos como comprar un esferográfico, y son dependientes de que se los proporcionen; 
además que persiste una diferencia marcada en la infraestructura y tecnología de la oferta universitaria dentro de la cárcel con respecto a la existente fuera de ella, pero también existen diferencias entre Centros, dificultando la transferencia igualitaria de conocimientos.

No se ha realizado un seguimiento profundo de los problemas que enfrentan los becarios en temas relacionados a la drogadicción, alimentación, salud, entre otros; ni tampoco se ha estudiado los motivos de deserción tanto en el contexto de encierro, como de aquellos que obtuvieron su libertad pero desistieron de la beca; impidiendo tomar los correctivos pertinentes para que no continúe esta grave ineficiencia.

Para poner en contexto la complejidad que puede tener el proporcionar educación en las cárceles, se asumirá el caso hipotético de un preso que no ha estudiado hace más de 20 años, tiene hábitos poco beneficiosos para el estudio, es adicto a las drogas y carece de buena salud, además padece de psicopatía no tratada, está mal alimentado y no duerme bien porque está perdiendo a su familia; pero la institución educativa le demanda que se concentre y haga deberes aunque carece de cuadernos porque los intercambio por drogas, y si le dan nuevos, seguramente lo volvería a hacer.

Basta con que ocurra uno de estos eventos para que la implementación del plan sea un desafío, pero cuando son más de dos y en distintos estudiantes con diferente combinación de estos y otros factores negativos, su efectividad se vuelve imposible sin el acompañamiento de otros actores como el Ministerio de Salud, la Policía Nacional, ONG, familiares del interno, etc.; es decir, que se requiere de toda la comunidad penitenciaria y no solamente de los profesores universitarios o de varios funcionarios del Ministerio de Justicia, quienes pueden tener las mejores intenciones y estar empoderados del proyecto, pero aún sus mayores esfuerzos serían insuficientes ante tan magna tarea caracterizada por un contexto cambiante y hostil, donde los avances pueden ser lentos pero los retrocesos agresivos.
El cumplimiento íntegro de los derechos humanos de las PPL, tanto en aspectos físicos como la correcta alimentación, el cuidado de la salud, la eliminación de la insalubridad y hacinamiento, etc.; y aspectos emocionales como el apoyo de sus seres queridos, el trato digno, entre otros; es una condición necesaria más no suficiente para que el SRS funcione, y con él, los proyectos emblemáticos como la provisión de Educación Superior en las cárceles.

La iniciativa, nueva en Ecuador pero no en América Latina, es teóricamente consistente, y aunque la cobertura es limitada, ha generado expectativas positivas sobre sus posibles productos. Vencer los múltiples obstáculos es imposible sin un monitoreo objetivo y multidisciplinario, que preferentemente debe ser realizado por agentes exógenos pero generando espacios para que los actores directos, no sólo agentes públicos sino también las PPL y sus familias debidamente representadas, tengan voz; permitiendo la identificación oportuna de desvíos así como la generación de correctivos, constituyéndose en un mecanismo relevante para el éxito del plan.

Ergo, el diseño participativo y la co-implementación de herramientas de seguimiento y evaluación, pueden ser ejecutadas no sólo por el Ministerio rector, sino también por un Observatorio Penitenciario que surgiría como una alternativa pertinente para medir los resultados, tanto de este proyecto como de la implementación global del SRS, abordando la etapa de encierro de las PPL y su posterior reinserción, evaluando los resultados e impactos, esto es, el cambio en la vida de los beneficiarios y la comunidad una vez que los internos recuperen su libertad, revelando en qué medida el sistema cumple su propósito aportando a la visión del Buen Vivir.

Las leyes y los discursos no cambian realidades, sino la acción directa de los actores, direccionados por un objetivo compartido cuyo resultado es deseado por todos. Aceptando el reto, Ecuador ha creado el marco, constituido por las normas que legitiman la acción, el lienzo se ha colocado a través de la planificación central 
y los objetivos de desarrollo, y se han dado los primeros trazos con el plan piloto que comprende al MJDHC, la SENESCYT y la Universidad; no obstante el cuadro final aún no está culminado.

Los costos económicos de estos programas difícilmente serán mayores a los costos sociales de la delincuencia, por lo cual la atención a las PPL es necesaria y urgente, más aún al considerar que en el marco del Buen Vivir, no hay espacio para la exclusión, así como en la era del conocimiento la verdadera inclusión es la inclusión en el conocimiento (Aguerrondo, 2008).

\section{Referencias bibliográficas}

Aguerrondo, I. (2008). Políticas de educación inclusiva. Conferencia Internacional de Educación (15-18). UNESCO.

Celis, R., \& Sepúlveda, C. (2012). Contra el despojo. Capitalismo, degradación ambiental y desplazamiento forzado. Bilbao: CEAR.

Constitución de la República del Ecuador. (2008). Ciudad Alfaro: Asamblea Constituyente.

Correa, R. (diciembre de 2008). Intervención conferencia magistral sobre el socialismo del siglo XXI. Recuperado de https://goo.gl/i9LDG2

Dias, J. (2008). Calidad, pertinencia y responsabilidad social de la universidad latinoamericana y caribeña. Tendencias de la Educación Superior en América Latina y el Caribe (87112). Cartagena: UNESCO.

Flores, P. (2005). Educación Superior y Desarrollo Humano. El caso de tres universidades tecnológicas. México: ANUIES - UIA.

INEA (2013). Educación para adultos en contexto de encierro. México: Instituto Nacional para la Educación de los Adultos.

Iturralde, C. (2005). Educación pública frente a educación privada en zonas urbano marginales de Guayaquil. Estudio de caso en Los Vergeles. Quito: FLACSO.

Larrauri, E. (1998). Criminología crítica: abolicionismo y garantismo. Lus et Praxis, 4(2), 27-64. Recuperado de https://goo.gl/wPBsqC

Ley Orgánica de Educación Superior (2010). Quito: Asamblea Nacional.

London, S., \& Formichella, M. (2006). El concepto de desarrollo de Sen y su vincula- ción con la Educación. Revista Economía y Sociedad, XI(17), 17-32. Recuperado de https://goo.gl/ulmZGT

Lutz, B. (2005). Reseña de 'Michel Foucault' y las prisiones de François Boullant. Revista Economía, Sociedad y Territorio, V(19), 659665. Recuperado de https://goo.gl/j1LNo3

Mandela, N. (1995). Un largo camino hacia la libertad. Madrid: Aguilar.

Messuti, A., Matus, J. P., Carrasco, E., Lagunas, C., Senesi, C., Eidem, M., y otros (2014). La rehabilitación social en el contexto latinoamericano. Quito: Ministerio de Justicia, Derechos Humanos y Cultos.

MJDHC (15 de mayo de 2015). Estado ecuatoriano promueve acceso a educación superior y técnica para PPL. Recuperado de https://goo.gl/tgkEfF

Nussbaum, M. (2006). Frontiers of justice. Disability, nationality, species membership. Londres: Belknap Press.

OAS (1948). Declaración Americana de los Derechos Humanos y Deberes del Hombre. Bogotá: OEA.

Obando, N., \& Ruiz, C. (2007). Determinantes socioeconómicos de la delincuencia: Una primera aproximación al problema a nivel provincial. Lima: CIES-CEDEP.

OEA (1988). Protocolo adicional a la Convención Americana sobre Derechos Humanos en materia de Derechos Económicos, Sociales y Culturales. Recuperado de https://goo.gl/fN2qVv

Parchuc, J. P. (2015). La Universidad en la cárcel: teoría, debates, acciones. Revista Redes de Extensión (1), 18-36. Recuperado de https://goo.gl/fs2Dyr

Pérez, C. (2013). Marcando al delincuente: estigmatización, castigo y cumplimiento del derecho. Revista Mexicana de Sociología, 75(2), 287311. Recuperado de https://goo.gl/gKJQyP

PIDESC (3 de enero de 1976). Pacto Internacional de Derechos Económicos, Sociales y Culturales. Recuperado de https://goo.gl/Fybgud

Ramírez, R. (2008). Igualmente pobres, desigualmente ricos. Quito: Ariel.

Scarfó, F. (2003). El derecho a la educación en las cárceles como garantía de la educación en derechos humanos. Revista IIDH, 36, 291 - 324. Recuperado de https://goo.gl/qADhGd

Scarfó, F. (2008). La educación pública en los establecimientos penitenciarios en Latinoamérica: garantía de una igualdad sustantiva. Educación 
en prisiones en Latinoamérica (111-142). Brasilia: UNESCO.

Sen, A. (2000). Desarrollo y libertad. Buenos Aires: Planeta.

SENPLADES (2012). ¡A (re)distribuir! Ecuador para todos. Quito: Secretaría Nacional de Planificación y Desarrollo.

SENPLADES (2013). Plan Nacional para el Buen Vivir 2013 - 2017. Quito: Secretaría Nacional de Planificación y Desarrollo.

UNESCO (14 de diciembre de 1960). Convención relativa a la Lucha Contra las Discriminaciones en la Esfera de la Enseñanza. Recuperado de https://goo.gl//ktb4AD

UNESCO (9 de marzo de 1990). Declaración Mundial sobre la Educación para Todos. Recuperado de https://goo.gl/Npa7e5

UNESCO (30 de marzo de 2007). Situación educativa de América Latina y el Caribe: Garantizando la Educación de Calidad para Todos. Recuperado de https://goo.gl/jDgiPP
UNESCO (10 de diciembre de 2008). Declaración Universal de Derechos Humanos. Recuperado de https://goo.gl/a7XLnH

UNESCO (2009). La nueva dinámica de la educación superior y la investigación para el cambio social y el desarrollo. Conferencia Mundial sobre la Educación Superior - 2009 (1-9). París: United Nations Educational, Scientificard and Cultural Organizations.

UNESCO (2015). La educación para todos, 2000 2015: logros y desafío. París: Organización de las Naciones Unidas para la Educación la Ciencia y la Cultura.

Urquijo, M. (2014). La teoría de las capacidades en Amartya Sen. Revista Edetania, 63-80. Recuperado de https://goo.gl/iGbXmr

Valenciano, G. (2009). Construyendo un concepto de educación inclusiva: Una experiencia compartida. En M. Sarto, \& M. Venegas, Aspectos clave de la educación inclusiva. 1ra. ed. (1324). Salamanca: INICO. 